\title{
ORAL INTRANEURAL PERINEURIOMA. REPORT OF TWO CASES
}

\author{
doi: $10.1590 / \mathrm{S} 1807-59322009001000017$
}

Lília Alves Rocha, Sílvia Maria Paparotto Lopes, Alan Roger dos Santos Silva, Márcio Ajudarte Lopes, Pablo Agustin Vargas

\section{INTRODUCTION}

A perineurioma is a benign nerve sheath tumor that can be classified as intra- or extraneural. Intraneural perineuriomas (IPs) are restricted to peripheral nerve boundaries and are rarely seen in the oral region, with only five cases reported in the English-language literature so far. ${ }^{1-5}$ Some authors believe that perineurioma is associated with trauma, but this association is not well-established in the literature. An IP is a cylindrical enlargement of a peripheral nerve that is formed by spindle-shaped cells around the nerve axon and expresses epithelial membrane antigen (EMA). ${ }^{1-5}$ This tumor usually affects adolescents and young adults, and it is not accompanied by pain or great increases in tumor size. ${ }^{1-5}$ The aim of this paper is to report two additional cases of oral IP to increase the current knowledge on this lesion and to discuss its etiopathogenesis.

\section{CASE DESCRIPTION}

\section{Case 1}

A 47-year-old white female was referred to the Oral Diagnosis Clinic for evaluation of a painless nodule on the tongue. According to her, the lesion had been present for almost 27 years and arose after a bicycle accident. Oral examination revealed a sessile and firm nodule measuring $1.0 \mathrm{~cm}$ in diameter located on the lingual apex (Figure 1A). The panoramic radiograph image did not show bone alteration. The patient related no motor or sensorial

Oral Pathology and Oral Semiology Sections, Piracicaba Dental School, University of Campinas - Piracicaba/São Paulo, Brazil.

Email: pavargas@ fop.unicamp.br

Tel.: 55192106.5319 alteration on the tongue. Clinical differential diagnosis included pyogenic granuloma and fibrous hyperplasia, and an excisional biopsy was performed.

\section{Case 2}

A 37-year-old black male HIV-positive patient presented to his private dentist for evaluation of a nodule that was present in the lower lip for 20 years. The patient did not complain of pain or increases in tumor size. Oral examination revealed a pediculadum nodule measuring $0.5 \mathrm{~cm}$ in diameter in the lower lip (Figure 1B). Panoramic radiographs showed nothing of note. The clinical differential diagnoses were fibrous hyperplasia and mucocele. An excisional biopsy was performed.

\section{Histopathological and immunohistochemical findings}

The specimens were immersed in $10 \%$ buffered formalin and were embedded in paraffin for processing and histopathological examination. Hematoxylin and eosin (H\&E) sections of both cases showed circumscribed lesions surrounded by fibrous connective tissue composed of layers of spindle-shaped cells around a central axon, forming structures described as onion-bulb-like (Figures 2 and 3A). Pleomorphic tumor cells, atypical mitotic figures and necrosis were absent. Immunohistochemical studies were carried out using the avidin-biotin complex technique. The perineurial cells showed strong immunoreactivity for EMA (Figure 3B) (E29 clone; Dakocytomation, Denmark A/S; dilution 1:400), while the Schwann cells were positive for S100 protein (Figure 3C) (Sigma-Aldrich, St Lois, MO; dilution 1:10,000). We used appropriate positive and negative controls for the immunoreactions, and the samples were treated according to standard protocols. Based on the histopathologic and immunohistochemical findings, the 


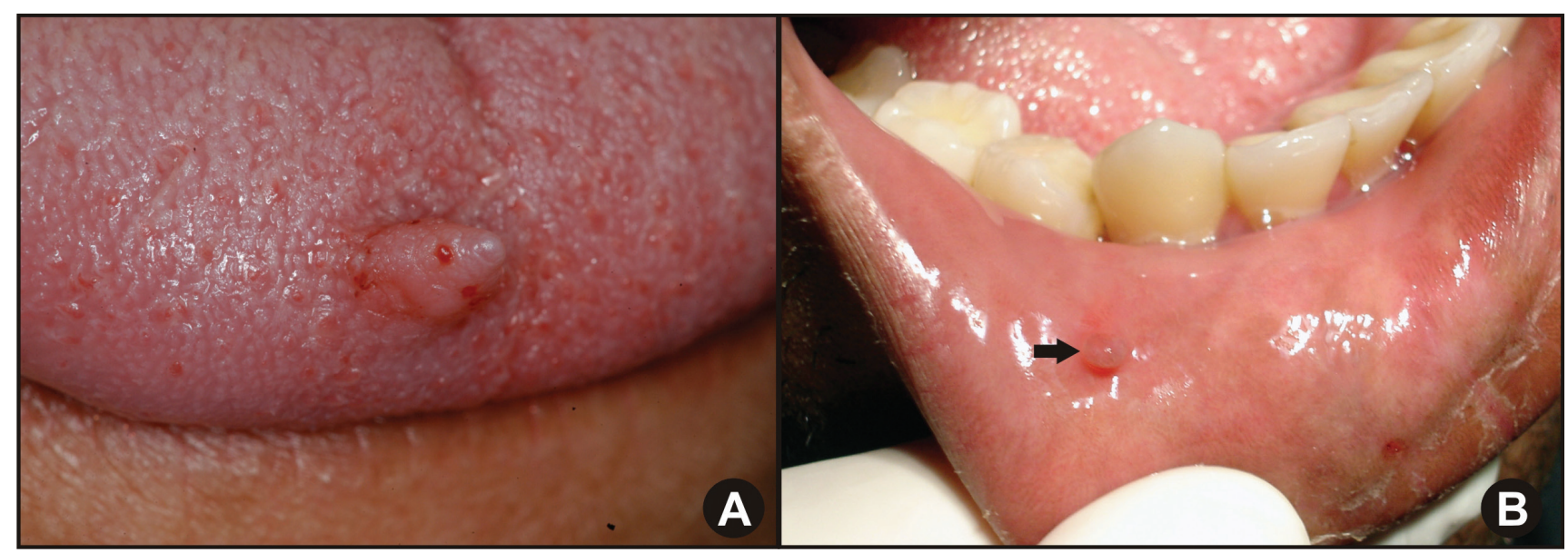

Figure 1 - A (Case 1) - A sessile nodule covered by filiform and erythematous fungiform papillae, located on the lingual apex. B (Case 2) - A small pediculadum nodule in the lower lip (black arrow)

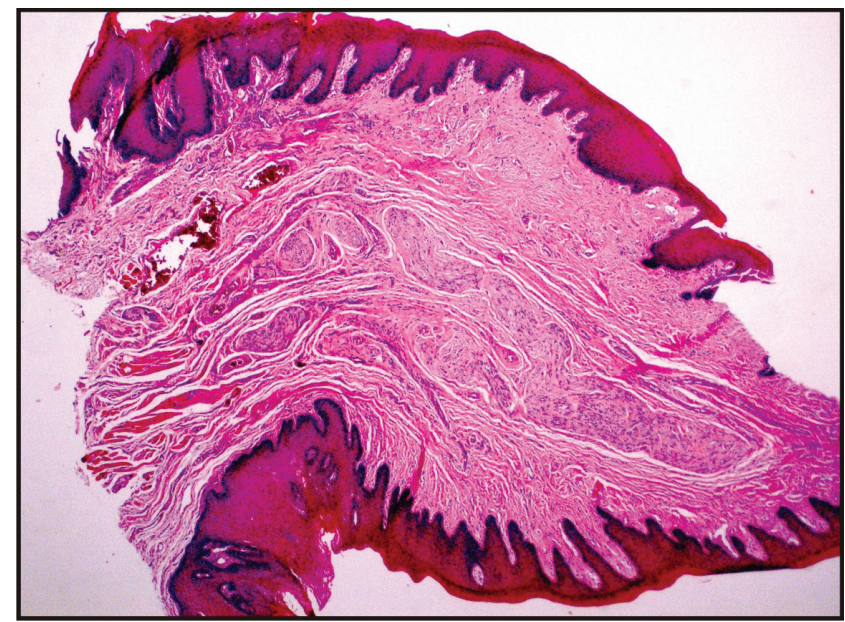

Figure 2 (Case 1) - Tortuous and well-circumscribed cellular proliferation of peripheral nerve boundaries ( $\mathrm{H} \& \mathrm{E}$, original magnification $\mathrm{x} 25$ )

diagnosis was oral IP in both cases. The scanning electron micrograph of IP was only illustrative (Figure 4) in case 1, but this technique can also be useful to confirm the diagnosis of perineurioma.

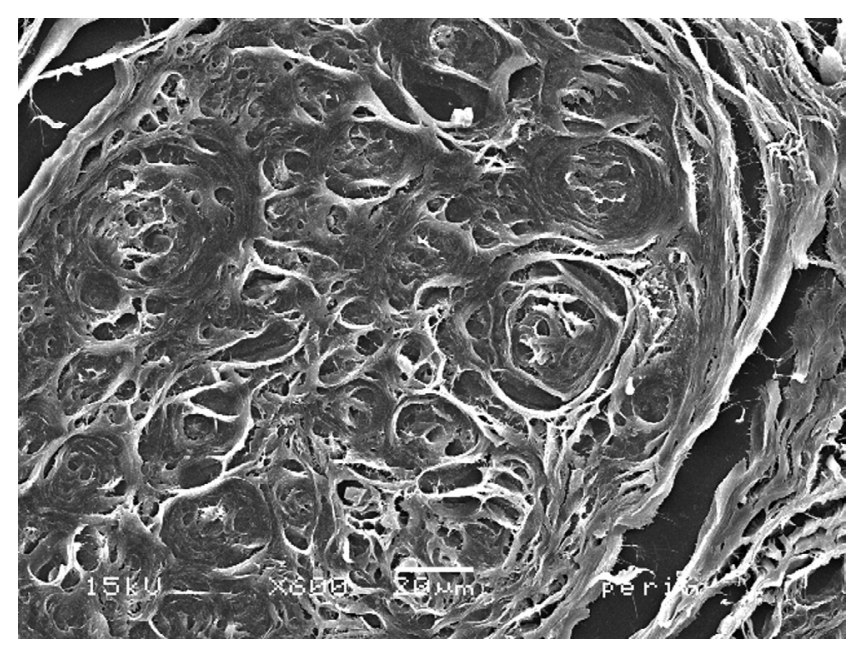

Figure 4 (Case 1) - Scanning electron micrograph showing onion-bulb-like structures. (x600)

\section{DISCUSSION}

IP occurrence in the mouth has been demonstrated, although its rarely occurs in oral region. Clinically, it

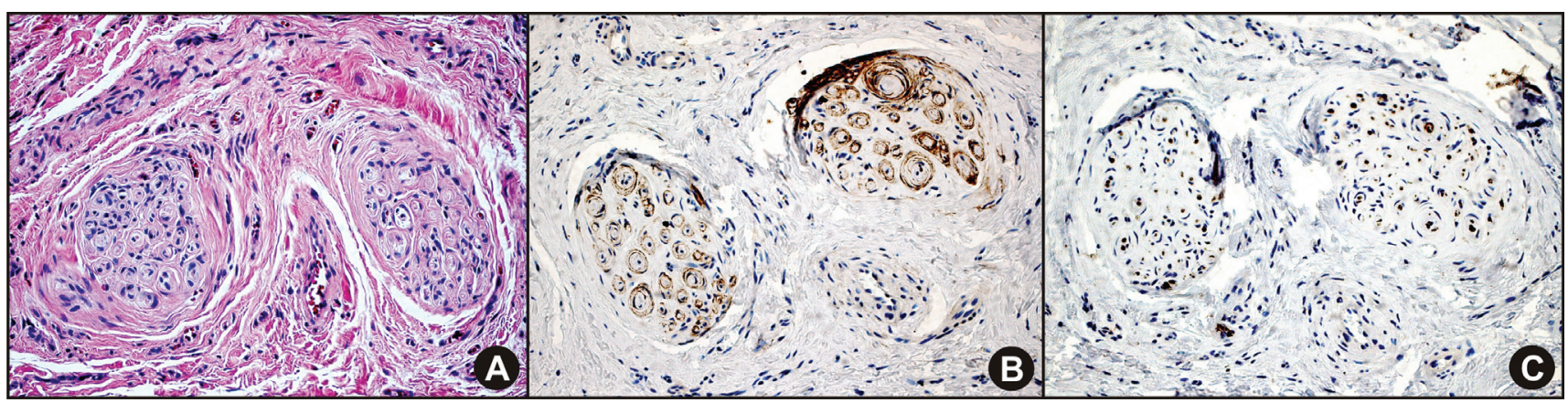

Figure 3 - A - Onion-bulb-like structures composed of central Schwann cells and axons surrounded by circumferential proliferation of spindle-shaped perineurial neoplastic cells (hematoxylin and eosin, original magnification x200). B - Perineurial cells immunoreactive for epithelial membrane antigen encircle negative Schwann cells and axons (original magnification x200). C - Immunoexpression of S-100 protein in the myelin sheath and Schwann cells, surrounded by perineurial cells that were negative for S-100 protein(original magnification x200) 
Table 1 - Summary of the reported cases of oral intraneural perineurioma, including the present cases

\begin{tabular}{|c|c|c|c|c|c|c|c|}
\hline Study & Age & Gender* & Site & Size $(\mathrm{cm})$ & $\begin{array}{c}\text { History of } \\
\text { trauma }\end{array}$ & Treatment & Recurrence \\
\hline Damm et al $(2003)^{3}$ & 26 & $\mathrm{~F}$ & Tongue & 0.75 & NA & Excisional biopsy & NA \\
\hline Hughet et al (2004) & 64 & M & Mandible & 2.0 & NA & Surgical enucleation & NA \\
\hline Perez et al $(2006)^{2}$ & 12 & M & Tongue & 0.6 & No & Excisional biopsy & No \\
\hline Boyanton et al $(2007)^{1}$ & 6 & $\mathrm{~F}$ & Tongue & 1.0 & No & Excision & No \\
\hline Dundr et al $(2007)^{4}$ & 16 & M & Oral mucosa & 1.5 & No & Excisional biopsy & No \\
\hline Current case 1 & 47 & $\mathrm{~F}$ & Tongue & 1.0 & Yes & Excisional biopsy & No \\
\hline Current case 2 & 37 & M & Oral mucosa & 0.5 & No & Excisional biopsy & No \\
\hline
\end{tabular}

* F, female; M, male; NA: not available.

produces a fusiform expansion of the nerve and can be associated with motor and sensory deficiency. ${ }^{1}$ However, these disturbances may not be reported when only small nerves are involved..$^{1-5}$ In the current cases, the patients presented with long-standing nodules diagnosed as IP and did not relate these deficits. The tumors presented as single painless nodules on the lingual apex and lower lip with no change in size. Until now in English-language literature, the mean age of the patients with intraoral IP was 29.7 years (range, 6 to 64 years), and the male-to-female gender ratio was 1.33 (Table 1).

Histological analysis showed that the perineurial cells proliferated around the axons and Schwann cells, that form onion-bulb-like structures. Immunohistochemical sections revealed EMA-positive perineurial cells around S100positive Schwann cells accompanying the axons. IP can be clinically misdiagnosed as other oral benign lesions. ${ }^{1-5}$ Thus, immunohistochemical studies are important to identify perineurial tumors and to exclude lesions such as fibrous hyperplasia, schwannoma, and neurofibroma, among others.

IP has a benign behavior and is not associated with invasion or metastasis. ${ }^{1}$ Despite the small number of intraoral perineuriomas reported in the literature, the treatment of choice is early complete excision of the lesion to minimize nerve damage..$^{1-5}$ Both cases presented here were completely excised, and no recurrences were detected after one year of follow-up in both cases. Recurrences of IP in the mouth have not been reported, ${ }^{1-5}$ confirming our findings (Table 1).

The etiology of IP remains uncertain, and it is unknown if the process is reactive or neoplastic. Some authors believe that the process arises from repeated trauma. However, others argue that patients rarely mention a history of trauma, and they are not convinced that trauma is causative. ${ }^{1-5} \mathrm{On}$ the other hand, abnormalities of chromosome 22 have been suggested as a neoplastic origin for perineuriomas. Case 1 strongly suggests a traumatic origin. The patient in case 2 was HIV positive, but, in our opinion, IP was only a coincident finding, and HIV may not be associated with the cause of the oral IP.

To the best of our knowledge, case 1 is the fourth IP on the tongue (Table 1). Two of these four cases have been diagnosed in our laboratory over a period of nearly two years. $^{2}$ Case 2 is the second IP arising from oral mucosa (Table 1). Interestingly, we diagnosed these IP cases almost simultaneously in our histopathological routine. It is possible that this is indicative that IP frequency is not as rare as previously mentioned and could be often mis-identified in oral pathology laboratories.

\section{REFERENCES}

1. Boyanton BL Jr, Jones JK, Shenaq SM, Hicks MJ, Bhattacharjee MB. Intraneural perineurioma: a systematic review with illustrative cases. Arch Pathol Lab Méd. 2007;131:1382-92.

2. da Cruz Perez DE, Amanajás de Aguiar FC Jr, Leon JE, Graner E, Paes de Almeida $\mathrm{O}$, Vargas PA. Intraneural perineurioma of the tongue: a case report. J Oral Maxillofac Surg. 2006;64:1140-42.

3. Damm DD, White DK, Merrell JD. Intraneural perineurioma not restricted to major nerves. Oral Surg Oral Med Oral Pathol Oral Radiol Endod 2003;96:192-6.
4. Dundr P, Povýsil C, Tvrdík D, Mazánek J. Intraneural perineurioma of the oral mucosa. Br J Oral Maxillofac Surg. 2007;45:503-4.

5. Huguet $\mathrm{P}$, de la Torre J, Pallarès J, Carrera M, Soler F, Espinet B, et al. Intraosseous intraneural perineurioma: report of a case with morphological, immunohistochemical and FISH study. Med Oral. 2004;9: 64-8 